\title{
Reciprocal Teaching and Comprehension of Struggling Readers
}

\author{
Humaira Raslie ${ }^{1}$, Damien Mikeng ${ }^{1} \&$ Su-Hie Ting ${ }^{1, *}$ \\ ${ }^{1}$ Centre for Language Studies, Universiti Malaysia Sarawak, 94300 Kota Samarahan, \\ Sarawak, Malaysia \\ *Corresponding author: Centre for Language Studies, Universiti Malaysia Sarawak, 94300 \\ Kota Samarahan, Sarawak, Malaysia. E-mail: shting@cls.unimas.my
}

Received: December 9, 2015 Accepted: January 15, 2015 Published: January 30, 2015

doi:10.5296/ije.v7i1.7027ＵRL: http://dx.doi.org/10.5296/ije.v7i1.7027

\begin{abstract}
This preliminary study examined the effect of reciprocal teaching on struggling readers' comprehension of a narrative text. The specific aspects studied were: (1) their suggestions to remake the ending of the narrative text based on preceding events; (2) their guided recall of details making up the gist of the narrative; and (3) their unguided recall of the gist of the narrative. The reciprocal teaching strategy was used to teach a literary text to 14 Malaysian struggling readers of English. The results showed that in the first lesson these students could not yet make links between the events of the story to suggest an alternative resolution of the narrative. Subsequently, their responses in the guided recall task showed that the four groups were able to supply the information making up gist of the story. However, the final unguided recall task showed that two groups usually provided their evaluation of their story and could remember only disparate details in the orientation of the story but could not recall major events. The findings suggest that a major challenge of implementing the reciprocal teaching strategy is guiding groups to share the task of monitoring their own comprehension through questioning, clarifying, summarizing and predicting.
\end{abstract}

Keywords: reciprocal teaching, reading comprehension, struggling readers, narrative text, recall 


\section{Introduction}

The reciprocal teaching strategy has been employed to structurally bridge the "discrepancy between decoding skills and comprehension skills" demonstrated by the students (Reichenberg \& Lofgren, 2014, p. 123). Reciprocal teaching is a reading instructional method that involves teachers and learners engaging in dialogues vis-à-vis a text (Ahmadi \& Ismail, 2012; Arif, 2014). Reciprocal teaching makes explicit use of four structured reading strategies, namely, summarising, questioning, clarifying and predicting in the context of direct but guided facilitation of active interactions between teacher-learner, learner-learner and learner-texts (Ahmadi \& Ismail, 2012). The notion of scaffolding can be seen in that there is a gradual shift of leadership from teacher to learner so that eventually the learners share the task of monitoring their own comprehension of the text with their teacher. To ensure that reciprocal teaching brings about holistic comprehension of learning topics and materials (Ismail, Ahmadi, \& Gilakjani, 2012), learners' background knowledge needs to be activated as they interact with the text context (Carter, 1997 cited in Ismail, Ahmadi, \& Gilakjani, 2012; Reichenberg \& Lofgren, 2014).

Studies on the use of the reciprocal teaching strategy have shown positive impacts on learners' reading comprehension. For example, in Sweden, Reichenberg and Lofgren (2014) found that after a three-month reciprocal intervention, grade three students living in a socially-disadvantaged neighbourhood demonstrated a significant increase in reading comprehension of Swedish texts. Similarly, Arif (2014) observed an improvement in the reading comprehension of 17 eleventh grade students of Muhamaddiyyah Secondary School, Pontianak, Indonesia after a reciprocal teaching intervention. The texts are presumed to be English texts. The usefulness of reciprocal teaching in the teaching of web programming language (Shadiev et al., 2013), metacognitive reading strategies (Ahmadi \& Ismail, 2012) and text comprehension of adults with intellectual disabilities (Alfassi, Weiss, \& Lifshitz, 2009; van den Box, Nakken, Nicholay, \& van Houten, 2007) have also been reported.

The literature has shown that reciprocal teaching can improve comprehension skills of struggling readers whose skills are compromised due to social and intellectual circumstances. Another limiting condition on reading comprehension is poor proficiency in the language. However, studies on text comprehension of second or foreign language learners and reciprocal teaching intervention are lacking although the technique was first developed three decades ago (Palincsar \& Brown, 1986). In countries like Malaysia where English is taught as the second language, poor proficiency in English has been found to hamper comprehension of the reading materials (Ghazali, Setia, Muthusamy, \& Jusoff, 2009; Hwang \& Embi 2007; Rashid, Vethamani, \& Rahman, 2010; Sidhu, Fook, \& Kaur, 2010). To help students make sense of reading texts, Malaysian teachers have resorted to using the students' native language such as Malay to explain the vocabulary and meanings of some parts of the texts (e.g., Hwang \& Embi, 2007; Rashid, Vethamani, \& Rahman, 2010; Sidhu, Fook, \& Kaur, 2010). In their study of 15 urban Malaysian schools, Hwang and Embi (2007) observed that teachers even asked students to read aloud the texts in unison and had to coach them to correctly pronounce the words. This strategy of teaching reading comprehension is often used in primary school (Sidhu, Fook, \& Kaur, 2010). 
When the texts are literary texts, the problem of struggling readers is compounded because the decoding of meaning takes place not at a literal level, but at an inferential level. Learners with a poor command of the language have difficulty not just in decoding the words in each line, but also reading in between and beyond the lines. Ghazali et al. (2009) found that Malaysian students are usually not very successful in decoding the literary texts on both surface and figurative terrains. In view of this, it is no surprise that teachers use a primarily teacher-centered approach in teaching literature (Ghazali et al., 2009; Hwang \& Embi, 2007; Samad, Aziz, \& Abdullah, 2008; Sidhu, Fook, \& Kaur, 2010). The students end up being passive learners listening to their teacher's summary of the texts, taking down dictation, memorizing new words, and reading-out-loud without much comprehension. Studies show that some students find the learning process dull and uninteresting (Hwang \& Embi, 2007), and full of anxiety as they are afraid of making mistakes (Ghazali et al., 2009) while others seem to respond positively to the literary presence in their English syllabus (Choo, Eng, \& Ahmad, 2011; Ismail, Aziz, \& Abdullah, 2008). In Malaysia, the Ministry of Education introduced the teaching of literature (the small "l") at form one level in secondary school and by 2005, abridged literary texts had been incorporated into the English syllabus for primary four, five and six (Ismail, Aziz, \& Abdullah, 2008). To achieve the goal of improving English competency through inculcating a reading habit, developing critical thinking and bridging contextual and cultural gaps of learning English, the literature component of the English syllabus is tested in the two national-level examinations at the end of form three and form five. However, as the findings have shown, a proportion of Malaysian students cannot even understand literary texts properly, let alone think critically about it. Given this educational backdrop, the need for innovative instructional strategies to help struggling readers in their comprehension of literary texts is needed.

Since the potential of reciprocal teaching to increase comprehension of literary texts has been relatively less explored, this study examined the effect of reciprocal teaching on struggling readers' comprehension of a narrative text. The specific aspects studied were: (1) their suggestions to remake the ending of the narrative text based on preceding events; (2) their guided recall of details making up the gist of the narrative; and (3) their unguided recall of the gist of the narrative. The use of recall as a comprehension measure is based on the premise that if the students have understood the narrative text, they would be able to create a different ending and remember the gist of it. Struggling readers in this paper refer to their dependency on others to decode and comprehend the text. In Brooks-Yip and Koonce's (2010) definition:

The difference between readers is not if they are struggling or not, it is a matter of being a dependent reader - one who counts on others to give them meaning, or an independent reader - one who has and employs his own strategies to comprehend any text. (p. 34)

\section{Method}

The participants of the study were 14 form 2 students aged 14 from a public school in Kuching, Sarawak, Malaysia: seven female students and seven male students. The students 
were of low to medium proficiency level in English based on their school examination performance. Their English teacher selected them for the study as they had poor reading and speaking skills. They hardly read books in English and speak English in their daily life, outside of their English class.

The second researcher carried out the reciprocal teaching intervention in four class sessions, 1 hour 20 minutes each, over a span of four weeks. The students had been briefed by their teacher on the purpose of the sessions which was to offer them an alternative and interesting way to learn the literary text.

In the first session, students were initially asked to read "One is One and All Alone" by Nicholas Fisk, one of the short stories in the English curriculum for Malaysian secondary schools. After the pre-reading activity for ice breaking and attention-getting, the students were given an exercise consisting of 10 multiple-choice questions based on the reading material to complete the task individually. While answering the questions, they were encouraged to discuss with a partner. In the process, they learnt to question their partner about the reading text, and questioning is one of the strategies in reciprocal teaching. Their responses for this task were not analysed because it was a typical reading comprehension lesson in the Malaysian context and did not draw on principles of reciprocal teaching. The session was mainly for the second researcher and the students to build a rapport for the subsequent reciprocal teaching intervention.

For the second session, students were divided into four groups of three to four members each $(\mathrm{G} 1, \mathrm{G} 2, \mathrm{G} 3, \mathrm{G} 4)$ to work as a team for the reading activity. They were given a crossword puzzle to complete as a group, and the words were based on the characters and setting of the story. For the group work, a leader was elected to read out the instruction and guide the members in the activity.

The third and fourth sessions were planned to give students practice on the four reciprocal teaching strategies (predicting, clarifying, questioning and summarizing). In the third session, the students were asked to remake the ending of the story (Table 2). They were also asked some factual questions about the story, intended as a guided recall task (Table 3). In the fourth session, they were asked to write down all the details they could recall about the story (Table 4). The unguided recall task drew upon their summarizing skill.

For the analysis of student responses in various tasks, the framework for the text organization of narratives was taken from Derewianka (1991) and Joyce and Feez (2000) which comprises orientation, complication and resolution. These are the stages that achieve the basic purpose of narratives to entertain, or additional purposes to teach values and 'embody the writer's reflections on experience, and - perhaps most important - to nourish and extend the reader's imagination" (Derewianka, 1991, p. 40). As explained by Derewianka (1991), in the orientation, the writer creates the possible world of the story and introduces the readers to the characters and the time and place of the story. Then a series of events follow leading to a complication which prevents the main character(s) from attaining their goal, and there may be a number of minor complications to sustain the reader's interest. Finally, the complication is resolved and the story ends. Feez and Joyce (1998) add evaluation which may occur at any 
stage. Based on the story "One is One and All Alone", the organizational structure of the story used for the analysis of students' recall is shown in Table 1.

Table 1. Organizational structure of narrative text

\begin{tabular}{ll}
\hline Story : One is One and All Alone & Text organization \\
\hline Time, place & Orientation \\
12 March 2045, left Earth for planet Trion & \\
Trish was in a spaceship where her father was the ship's Executive & \\
Officer. &
\end{tabular}

Major events

Complication

1. Trish was on a spaceship heading to planet Trion.

2. Trish learned from VP (Voice Printer) about cloning techniques in the BioLab.

3. A clone was created to her likeness and was given a name; Clo for Clone.

4. At first, they were best friends but eventually Trish started to feel annoyed at Clo as she claimed all Clo does was interrupting her train of thought.

Final event Resolution

1. Trish planned to get rid of Clo with the disposal system.

2. The new Trish (Clo) smiled as she enjoyed her chocolate milkshake.

Examples: (Students') evaluation

1. We should love ourselves and family.

2. Trish should not create a clone.

3. Having a clone is interesting but can be dangerous.

4. Every individual is unique and differences between people are normal.

\section{Results and Discussion}

\subsection{Remaking of the ending of the story}

The students were given an excerpt of the last part of a chapter to read and it suggests that Trish may dispose of her annoying clone, Clo, in the disposal system of the spaceship. The students were asked to propose two other ways of solving the problem of the annoying clone and an example was given for the sentence structure which could be used to make suggestions, "I think I should share my problems with my family." This was a group task, facilitated by the group leader because one of the principles of reciprocal teaching is to train students to develop the skills of asking questions, identifying unclear information that needs clarification, and summarizing. However, the students gave responses which seemed to stray from the unfinished story. Their responses revolved around desirable student activities such as doing homework every day with friends, being hardworking, and spending more time with the family and undesirable activities such as playing computer games and watching television 
(Table 2).

Table 2. Students' responses on remaking the ending of the story in groups

\begin{tabular}{ll}
\hline Suggestions of other ways to solve the problem & Groups \\
\hline I think I should be with my family more often & G1 \\
I think I should do homework together with my friends & G1, G2, G3, G4 \\
I think I should do homework every day & G2 \\
I think I should be hardworking from now on & G4 \\
I think I should not play games & G1, G3, G4 \\
I think I should not spend time on computer & G4 \\
I think I should not spend time on TV & G4 \\
\hline
\end{tabular}

The students seemed to have responded to the example given rather than the excerpt of the unfinished story. Of all the responses given, only one was related to the story, that is, "I think I should be with my family more often" given by G1. This is because the protagonist in the story, Trish, was an only child and lonely and spent most of her time with her Voice Printer as her mother was already in planet Trion, the place where they were heading. Her father, the spaceship's executive officer, was too busy manning the ship to spend time with her. The inability of these students to give appropriate responses to remake the ending of the story suggests that their reading comprehension was poor and they could not process links between related information placed on a page, but responded to the instruction right above the blank boxes they were asked to write their suggestions in. To add to the difficulty, remaking the ending of the story required them to remember and understand the events leading up to Trish's annoyance with her clone and use their background knowledge on dealing with sibling problems to suggest alternative solutions.

\subsection{Guided recalling of the gist of the story}

The task sheet had a sketch of a sad-looking Trish standing by a window as the background, and four questions were placed in four circles to elicit the gist of the story. Table 3 shows the students' responses on the gist of the story.

Table 3. Guided recall of details making up the gist of story by groups of students

\begin{tabular}{|c|c|c|}
\hline Questions to elicit gist of story & Student responses & Groups \\
\hline $\begin{array}{l}\text { 1. The story takes place in (past, present, } \\
\text { future). }\end{array}$ & Future & $\mathrm{G} 1, \mathrm{G} 2, \mathrm{G} 3, \mathrm{G} 4$ \\
\hline \multirow[t]{2}{*}{ 2. The main characters are: } & Trish \& Clo & G1, G2, G3, G4 \\
\hline & Dad & G3 \\
\hline \multirow{2}{*}{$\begin{array}{l}\text { 3. The problem of the story begins } \\
\text { because the main character is }\end{array}$} & Lonely & G1, G2, G3 \\
\hline & Trish, Clo, Mum \& Dad & G4 \\
\hline \multirow[t]{2}{*}{$\begin{array}{l}\text { 4. What have you learnt from this story? } \\
\text { What are the moral values? }\end{array}$} & $\begin{array}{l}\text { Never keep your } \\
\text { problems to yourself }\end{array}$ & G1, G2, G3 \\
\hline & Be grateful & G2, G4 \\
\hline
\end{tabular}


The setting was simplified to a choice of past, present or future, and all the four groups of 14 students answered the question correctly. The story was set in the future when people could travel to space, and it is clearly mentioned that Trish would reach Trion by mid-January 2047. Next, three groups of students identified the main characters as Trish and her clone, Clo, but G3 also mistakenly listed Trish's Dad as the main character. His role in the story was minor and in the chapter they were asked to read, Trish's Dad only appeared in the earlier part of story as found in the fourth and last paragraphs of the story. Other than this, the students were clear on the orientation of the story.

As for the complication in the story, Table 3 shows that three groups identified the problem as Trish being lonely but G4 responded to the second part of the question (The problem of the story begins because the main character is ...) and listed the four characters in the story. This is a problem of reading information in the immediate vicinity of the answer spaces. The same problem surfaced when they were asked to give responses on remaking the ending of the story, as highlighted earlier (Table 2). Finally, they were asked to provide an evaluation of the story in the form of moral values they took away from the story, and the students felt that the story taught them not to keep their problems to themselves (G1, G2, G3) or else they would end up destroying themselves in the process. G2 and G4 also felt that the story taught them to be grateful. In the story, the main character Trish was feeling sick being the only child in the spaceship, and she had created a clone of herself. This clone would later become sinister and take her position. Their responses showed that the four groups were able to supply the pieces of information making up gist of the story in the guided recall task.

\subsection{Unguided recalling of the story}

The open-ended individual task required students to recall any detail they could remember from the story, and served as an alternative to guided questions to elicit the gist of the story. Table 4 (last column) shows that the number of pieces of information recalled varies from three to 22 , but a higher number is usually not better. This is because students like Lee (G2) could list 22 details but they were merely disparate pieces of information (see example below):

\begin{tabular}{l|l|l|l}
\hline Trish is good & Sad story & Ship & Disposal \\
Clone & VP - voice printer & Executive officer & Diary \\
Trion & Pop-star & Trish's Mum & Earth \\
Clo is bad & 2045 & Enormous screen & Trish's favourite \\
Chocolate milkshake & Trish is lonely & Towel & game is popstar \\
One is one and all alone & Clo is bad technology & Toothbrushes & \\
\hline
\end{tabular}

G1 and G2 members tended to write down a series of details (e.g., Trish, Clo, Mum, Dad, Pop Star, Voice Printer, chocolate milkshake) and descriptors (e.g., Clo is bad, Trish is good, Clone is a technology) but the details are not linked. For example, it is not clear what Pop Star and Voice Printer refer to. The details that these two groups could link are the setting (e.g., "left earth in 2014, reach Trion in mid-January 2047", Yong, G1) and the evaluation (e.g., I think the story is sad because Trish is always alone in the spaceship", Yong, G1). In the listing of details recalled from the story, many students did not put "Clo" and the clone 
together as one and the same person. What can be concluded from the recall of G1 and G2 members is that their understanding of the storyline is probably fuzzy. What is important is not the number of details recalled but how the details are linked in the recall because this reflects their comprehension of the story.

Table 4. Individual students' recall of the gist of the story

\begin{tabular}{|c|c|c|c|c|c|c|c|}
\hline Group & Student & Setting & Characters & $\begin{array}{l}\text { Major } \\
\text { events }\end{array}$ & Resolution & Evaluation & $\begin{array}{c}\text { Number of } \\
\text { details } \\
\text { recalled }\end{array}$ \\
\hline G1 & $\mathrm{Gab}$ & $\checkmark$ & $\checkmark$ & $X$ & $X$ & $\checkmark$ & 15 \\
\hline G1 & Yong & $\boldsymbol{\nu}$ & $\checkmark$ & $X$ & $X$ & $\checkmark$ & 9 \\
\hline G1 & Wong & $\checkmark$ & $\checkmark$ & $X$ & $X$ & $\checkmark$ & 8 \\
\hline $\mathrm{G} 2$ & Yuki & $\checkmark$ & $\checkmark$ & $\mathrm{X}$ & $\mathrm{X}$ & $X$ & 10 \\
\hline $\mathrm{G} 2$ & Lee & $\checkmark$ & $\checkmark$ & $X$ & $X$ & $\checkmark$ & 22 \\
\hline $\mathrm{G} 2$ & Voon & $\checkmark$ & $\checkmark$ & $X$ & $X$ & $\checkmark$ & 10 \\
\hline $\mathrm{G} 2$ & $\mathrm{Fu}$ & $X$ & $\checkmark$ & $X$ & $X$ & $X$ & 18 \\
\hline G3 & $\mathrm{C}$ & $\checkmark$ & $\checkmark$ & $X$ & $\checkmark$ & $\checkmark$ & 5 \\
\hline G3 & Yong & $X$ & $\checkmark$ & $\checkmark$ & $\checkmark$ & $\checkmark$ & 7 \\
\hline G3 & Jeff & $X$ & $\checkmark$ & $X$ & $\checkmark$ & $\checkmark$ & 5 \\
\hline G3 & Mary & $\checkmark$ & $\checkmark$ & $X$ & $\checkmark$ & $\checkmark$ & 6 \\
\hline G4 & Liew & $\checkmark$ & $\checkmark$ & $\mathrm{X}$ & $X$ & $X$ & 3 \\
\hline G4 & Desmond & $\checkmark$ & $\checkmark$ & $X$ & $X$ & $\checkmark$ & 8 \\
\hline G4 & Sim & $\checkmark$ & $\checkmark$ & $X$ & $\checkmark$ & $\checkmark$ & 8 \\
\hline Total & $\begin{array}{l}14 \\
\text { students }\end{array}$ & 11 & 14 & 1 & 5 & 11 & \\
\hline
\end{tabular}

The details they gave were analysed in terms of the setting, characters, major events, resolution and evaluation. Table 4 shows that all the 14 students remembered the main characters in the story, and a majority of them recalled the setting (place and time, or both) and mentioned their evaluation of the story. However, only one wrote down some major events in the story and five recalled the resolution of the story, often in connection with their evaluation of the story. These results concur with Table 3 whereby all the groups correctly answered the questions on the setting and the characters in the story.

Among the four groups, G3 and G4 had better recall of the story "One is One and All Alone". The best storyline was given by Yong from G3:

This story has four people: Dad, Mum, Trish and Clo. [Characters]

This is a sad story because Trish die in Disposal. [Evaluation, Resolution]

Trish is good. [Character details]

Clo is bad. [Character details]

Clo has many happens to Trish. [Major events] 
Clo push Trish in Disposal. [Major events]

Only the orientation (on a spaceship heading to planet Trion by 2047) was missing from Yong's recall. Yong was the only student out of 14 who listed some major events from the story. A complete recall is shown in Table 1. The other G3 members had the resolution, which was often given with the students' feelings about the story along the lines of "This is a sad story because Trish die[s] in 'Disposal"' (G3, Mary) and "This is a sad story because in the end, Clo kills Trish" (G4, Sim). In short, the recall of most students in this study comprised the orientation, resolution and evaluation but they did not remember the other events in the plot.

The results on the struggling readers' focus on the orientation of the narrative concur with Ghazali et al.'s (2009) findings. Out of 110 students from Kemaman, Terengganu, Malaysia, $97 \%$ thought that background information concerning a text such as the author's life or the setting was vital to understanding a text, and $91.8 \%$ of the students were keen on doing group work in the literature class, as it gave them an opportunity to voice their opinions and personal reactions concerning the texts that they read. Ghazali et al.'s findings suggest that the students' tendency to provide their orientation of the story in the present study could be a response to their teacher's emphasis on the background of the story as the review of studies conducted in Malaysia shows that teachers are similar in their way of teaching reading comprehension. Although ability to offer a personal reaction to the text is at the level of evaluation, beyond that of literal comprehension of the text, the struggling readers had difficulty synthesizing the main events of the story to lead to the resolution. It is more difficult for struggling readers to synthesize the story than to express their feelings on the ending of the story in a one-liner. According to the revised Bloom's (1956) taxonomy, synthesis is placed as the highest level of cognitive skills, above evaluation (Anderson \& Krathwohl, 2001).

In the context of reciprocal teaching, having peers to facilitate group discussion and group tasks may help certain groups like G3 who seemed to perform well individually as well as in the group. The reciprocal teaching did not seem to have aided the unguided recall of G1 and G2. Observations had also indicated that the two groups who were less effective in the group work (G1 and G2) also had poorer recall of the narrative in the unguided recall task. These two groups were less dynamic working in a team. Their leaders were not able to direct their peers to monitor their comprehension. There were few instances of questioning and attempts to clarify their understanding of the narrative text. The members of the two groups who produced a list of isolated details about the story also did not help one another in constructing a summary of the story in the unguided recall task. Both G1 and G2's leaders were struggling to lead the groups and they required more time to complete the tasks compared to the other two groups. G3 and G4 had a good discussion going, and the members even took turns to pose questions and direct the discussion, indicating that there was a sharing of leadership. These two groups were able to outline the major events in the story. This study indicates that the difficulty in reciprocal teaching intervention is not getting learners to understand what predicting, clarifying, questioning and summarizing are because these can be elicited through well-designed tasks, but to teach them to take turns to monitor the comprehension of their 
peers. This is because the group leadership skill takes time to develop and cannot be shown in four weeks, which was duration of the present reciprocal teaching intervention. Other studies using the reciprocal teaching strategy have used three months (e.g., Reichenberg \& Lofgen, 2014). For reciprocal teaching to be put to good use, a plan needs to be put in place to train the learners to use strategies to monitor comprehension of peers in the collaborative social activity.

\section{Conclusion}

The study showed some positive effects of reciprocal teaching on struggling readers' comprehension of a narrative text, as evidenced by their unguided recall of the gist of the narrative. Out of the four groups, two were able to outline the orientation, major events and resolution of the narrative, and these two groups demonstrated better group dynamics in that the leader was effective in monitoring the group members' comprehension through questioning and clarifying information given. The other two groups tended to recall disparate details concerning the setting and characters in the story and offered their evaluation of the story, but the details were not linked as events. This preliminary study showed that using unguided recall to elicit the gist of the story is probably a better measure of comprehension than guided recall using comprehension questions or remaking the ending of the narrative because the latter does not tap into the skill of synthesizing a literary text. However, the findings are merely indicative due to the short duration of the reciprocal teaching intervention which does not allow skills in monitoring peer's comprehension to develop sufficiently. Further studies using a longer duration for the reciprocal teaching intervention with more scaffolding and modelling on using questioning, clarifying, predicting and summarizing strategies as well as training on leading group work may offer a more student-centred approach towards developing reading comprehension skills.

\section{References}

Ahmadi, M. R., \& Ismail, H. N. (2012). Reciprocal teaching strategy as an important factor of improving reading comprehension. Journal of Studies in Education, 2(4), 153-173. http://dx.doi.org/10.5296/jse.v2i4.2584

Alfassi, M., Weiss, I., \& Lifshitz, H. (2009). The efficacy of reciprocal teaching in fostering the reading literacy of students with intellectual disabilities. European Journal of Special Needs Education, 24, 291-305. http://dx.doi.org/10.1080/08856250903016854

Anderson, L. W., \& Krathwohl, D. R. (Eds.). (2001). A taxonomy for learning, teaching, and assessing: A revision of Bloom's taxonomy of educational objectives. New York: Longman.

Arif, A. (2014). Increasing the students' reading comprehension by using reciprocal teaching strategy. Jurnal Pendidikan Bahasa, 3(1), 1-14. 
Bloom, B. S. (Ed.) (1956). Taxonomy of educational objectives: The classification of educational goals - Handbook I: Cognitive Domain. New York: McKay.

Brooks-Yip, M., \& Koonce, J. B. (2010). Taking another look at struggling adolescent readers. Language Arts Journal of Michigan, 26(1), 33-37. http://dx.doi.org/10.9707/2168-149X.1015

Carter, C. (1997). Why reciprocal teaching? Educational Leadership, 54(6), 64-69.

Choo, T. L. O., Eng, K. T., \& Ahmad, N. (2011). Effects of reciprocal teaching strategies on reading comprehension. The Reading Matrix, 11(2), 140-149.

Derewianka, B. (1991). Exploring how texts work. Sydney, Australia: Primary English Teaching Association.

Feez, S., \& Joyce, H. (1998). Text-based syllabus design. Sydney, Australia: Macquarie University.

Ghazali, S. N., Setia, R., Muthusamy, C., \& Jusoff, K. (2009). ESL students' attitude towards texts and teaching methods used in literature classes. English Language Teaching, 2(4), 51-56. http://dx.doi.org/10.5539/elt.v2n4p51

Hwang, D., \& Embi, M. A. (2007). Approaches employed by secondary school teachers to teaching the literature component in English. Jurnal Pendidik Dan Pendidikan, 22, 1-23.

Ismail, F, A. A., Aziz, M, \& Abdullah, T. (2008). Literature in English language teaching: A revisit in the Malaysian context. In M. A. N. Omar \& Z. Zainal (Eds.), Research in Language Teaching (pp. 53-68). Johor Bahru, Malaysia: Universiti Teknologi Malaysia Press.

Ismail, H. N., Ahmadi, M. R., \& Gilakjani, A. P. (2012). The role of reciprocal teaching strategy as an important factor of improving reading motivation. Elixir Educational Technology, 53, 11836-11841. Ismail, Ahmadi, \& Gilakjani

Joyce, H., \& Feez, S. (2000). Writing skills: Narrative and non-fiction text types. Sydney: Phoenix Education Pty Ltd.

Palincsar, A. S., \& Brown, A. L. (1986). Interactive teaching to promote independent learning from text. The Reading Teacher, 39(8), 771-777.

Rashid, R. A., Vethamani, M. E., \& Rahman, S. B. A. (2010). Approaches employed by teachers in teaching literature to less proficient students in Form 1 and Form 2. English Language Teaching, 3(4), 87-99. http://dx.doi.org/10.5539/elt.v3n4p87

Reichenberg, M., \& Lofgren, K. (2014). An intervention study in Grade 3 based upon reciprocal teaching. Journal of Education and Learning, 8(2), 122-131.

Samad, A. A., Aziz, M., \& Abdullah, T. (2008). Teachers' perceptions of literature circle as a technique to teach creative writing using texts. In M. A. N. Omar \& Z. Zainal (Eds.), Research in Language Teaching (pp. 27-52). Johor Bahru, Malaysia: Universiti 
Teknologi Malaysia Press.

Shadiev, R., Hwang, W. Y., Yeh, S. C., Yang, S. J. H., Wang, J. L., Han, L., Huang, Y. M., \& Liu, C. J. (2013). Applying unidirectional versus reciprocal teaching strategies in web-based environment and their effects on computer programming learning. Proceedings of 2013 IEEE $13^{\text {th }}$ International Conference on Advanced Learning Technologies, pp. 5-9. http://dx.doi.org/10.1109/ICALT.2013.7

Sidhu, K. G., Fook, Y. F., \& Kaur, S. (2010). Instructional practices in teaching literature: Observations of ESL classrooms in Malaysia. English Language Teaching, 3(2), 54-63. http://dx.doi.org/10.5539/elt.v3n2p54

van den Bos, K. P., Nakken, H., Nicholay, P. G., \& van Houten, E. J. (2007). Adults with mild intellectual disabilities: Can their reading comprehension ability be improved? Journal of Intellectual Disability Research, 51, 835-849. http://dx.doi.org/10.1111/j.1365-2788.2006.00921.x

\section{Copyright Disclaimer}

Copyright for this article is retained by the author(s), with first publication rights granted to the journal.

This is an open-access article distributed under the terms and conditions of the Creative Commons Attribution license (http://creativecommons.org/licenses/by/3.0/). 